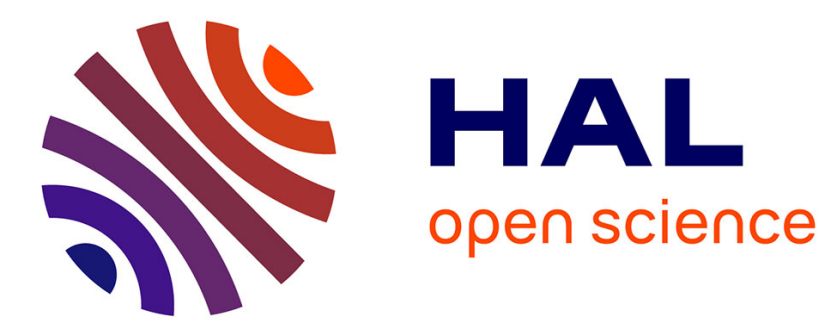

\title{
Electric vehicle fleet contributions for isolated systems. The case of the Canary Islands
}

\author{
Gustavo A Marrero, Yannick Perez, Marc Petit, Francisco Javier Ramos-Real
}

\section{To cite this version:}

Gustavo A Marrero, Yannick Perez, Marc Petit, Francisco Javier Ramos-Real. Electric vehicle fleet contributions for isolated systems. The case of the Canary Islands. International Journal of Automotive Technology and Management, 2015, 15, pp.171 - 171. 10.1504/IJATM.2015.068552 . hal01424629

\section{HAL Id: hal-01424629 \\ https://hal.science/hal-01424629}

Submitted on 5 Jan 2017

HAL is a multi-disciplinary open access archive for the deposit and dissemination of scientific research documents, whether they are published or not. The documents may come from teaching and research institutions in France or abroad, or from public or private research centers.
L'archive ouverte pluridisciplinaire HAL, est destinée au dépôt et à la diffusion de documents scientifiques de niveau recherche, publiés ou non, émanant des établissements d'enseignement et de recherche français ou étrangers, des laboratoires publics ou privés. 


\title{
Electric vehicle fleet contributions for isolated systems. The case of the Canary Islands
}

\author{
Gustavo A. Marrero \\ Departamento de Análisis Económico, \\ Universidad de La Laguna, \\ Camino la Hornera, s/n., \\ 38071 San Cristóbal de La Laguna, \\ Santa Cruz de Tenerife, Canary Islands, Spain \\ and \\ Instituto Universitario de Desarrollo Regional, \\ Facultad de Ciencias Económicas, \\ Universidad de La Laguna, \\ Camino la Hornera, s/n., \\ 38071 San Cristóbal de La Laguna, \\ Santa Cruz de Tenerife, Canary Islands, Spain \\ Email: gmarrero@ull.es
}

\section{Yannick Perez}

Supélec,

3 Rue Joliot Curie, Plateau de Moulon,

91190 Gif-sur-Yvette, France

and

RITM,

University Paris-Sud,

15 Rue Georges Clemenceau, 91400 Orsay, France

and

Armand Peugeot Chair,

Centrale-Supélec and ESSEC Business School Paris,

1 Avenue Bernard Hirsch, 95021 Cergy-Pontoise, France

Email: yannick.perez@u-psud.fr

\section{Marc Petit}

Department of Power and Energy Systems,

E3S SUPELEC Systems Sciences,

Gif-sur-Yvette, France

and

Armand Peugeot Chair,

Centrale-Supélec and ESSEC Business School Paris,

1 Avenue Bernard Hirsch, 95021 Cergy-Pontoise, France

Email: marc.petit@supelec.fr 


\section{Francisco Javier Ramos-Real*}

Departamento de Análisis Económico, Universidad de La Laguna,

Camino la Hornera, s/n., 38071 San Cristóbal de La Laguna, Santa Cruz de Tenerife, Canary Islands, Spain and Instituto Universitario de Desarrollo Regional, Facultad de Ciencias Económicas, Universidad de La Laguna,

Camino la Hornera, s/n., 38071 San Cristóbal de La Laguna, Santa Cruz de Tenerife, Canary Islands, Spain Email: frramos@ull.es

*Corresponding author

Abstract: The Canary Islands offer an example of an isolated electric grid of relatively important size within the EU. Generally, these systems do not have access to every technology available, nor can they be connected to continental grids when necessary. Due to their particularities, renewable energies, benefitting from their complementarity with fossil fuels, can play an important role in achieving the main energy policy goals of the islands. Electric vehicles (EVs), thanks to their storage capacity, can provide benefits to the power system reducing both the need for backup thermal generation and the amount of spilled renewable energy (mainly wind). Moreover, EVs can introduce more demand flexibility, which reduces the extra costs (intermittency costs) that renewable technologies impose on power systems. Comparing an efficient mix under a baseline scenario (null impact of electric vehicles) with an equivalent efficient mix under an alternative scenario assuming the introduction of a maximum of 122,000 cars into the Canarias market in 2025, we find a reduction of almost $11 \%$ in average generating cost (about 80 million euros/year), $9 \%$ in risk (measured as the standard deviation) and almost $13 \%$ in emissions.

Keywords: electricity generating cost; electric vehicles; efficiency frontiers; isolated electricity systems.

Reference to this paper should be made as follows: Marrero, G.A., Perez, Y., Petit, M. and Ramos-Real, F.J. (2015) 'Electric vehicle fleet contributions for isolated systems. The case of the Canary Islands', Int. J. Automotive Technology and Management, Vol. 15, No. 2, pp.171-193.

Biographical notes: Gustavo A. Marrero is an Associate Professor (with Tenure) of the Department of Economics at the University of La Laguna and coordinates the Research Group of Economic Development, Energy and Transport. He has published in leading journals of energy and economics such as J. of Development Economics, Energy Economics, Energy Policy, J. of Economic Dynamics and Control, etc. He has coordinated several research projects related with energy efficiency and climate change financed by the Spanish Ministry and FEDEA. 
Yannick Perez received his PhD in Economics (2002) from the University Paris 1 Panthéon-Sorbonne. He became a tenured Associate Professor at the University Paris-Sud in 2003. Since 2008, he is a Chief Economic Advisor of the Loyola de Palacio Chair at the European University Institute (Florence). Since 2011, he is also an Associate Professor of Economics at Supélec. From 2012, he joined the Armand Peugeot Research Chair as a researcher. Since the last 15 years, he has published extensively in energy related topics including contribution in ecological economics, energy policy, and renewable and sustainable energy review.

Marc Petit is a former student of the Ecole Normale Supérieure de Cachan (France). He holds a PhD thesis in 2002 in Electrical Engineering. Since 2003, he is an Associate Professor in Supelec in the Power and Energy System Department where he currently manage the power system group. Since 2011, he is the co-Head of the Armand Peugeot Research Chair on Electromobility. His research interests are on smart grids, demand response, power system protection and HVDC supergrids.

Francisco Javier Ramos-Real is an Associate Professor (with tenure) of the Department of Economics, Accounting and Finance at the University of $\mathrm{La}$ Laguna (ULL) and coordinator of the Research Group of Economics of Productivity, Energy and Transport (ULL). He has directed numerous works in the field of energy economics and published in leading journals in the specialty as energy economics or energy policy. He has also coordinated several projects related to the preparation and subsequent revision of the Energy Plan of the Canaries (PECAN, 2006).

This paper is a revised and expanded version of a paper entitled 'EV fleet contributions for isolated systems. The case of Canary Islands' presented at the International Conference Electromobility: Challenging Issues, Paris, 19-20 December 2013.

\section{Introduction}

Isolated grids feature a set of characteristics that usually imply a greater energy dependency and vulnerability, thus creating a need for specific planning. The Canary Islands represent a clear example of an isolated energy system of relatively important size within the EU. Generally, these systems do not have access to every technology available, nor can they be connected to continental grids when necessary. Nearly all small islands in the world are totally dependent on fossil fuels for their energy needs. In small and isolated systems, where energy needs are reduced, small diesel units are preferred. This improves reliability as group tripping has fewer negative consequences. The flexibility criteria often favour diesel groups and small-scale hydro, if the geography is suited to such solutions. Diesel groups have two drawbacks: very high generation costs and high level of pollution. In the Canary Islands, the mix of primary energy, such as electricity generation, depends on oil derivatives in more than $90 \%$. Due to their peculiarities, renewable energies, complementary as they are with fossil fuels, can provide a reliable means of achieving the main energy policy goals as regards the Islands' emissions (Perez and Ramos-Real, 2008, 2009). Canaries energy plan 2006 (PECAN, 2006) was the document that set the basic energy policy objectives for the Canary 
Islands. The set of measures in PECAN (2006) allows the archipelago energy system to reduce both emission levels and its dependence on oil thanks to the introduction of natural gas and an increased reliance on renewable energies ${ }^{1}$.

In this framework, electric vehicles (EVs), with their added storage capacity can provide benefits to the power system by reducing both the need for backup thermal generation and the amount of spilled renewable energy (mainly wind) due to the lack of demand or transmission capacity. Moreover, EVs can introduce more demand flexibility to reduce the extra costs (intermittency costs) that renewable technologies impose on power systems. A higher share of renewables in the electricity generating mix could induce a more efficient energy diversification and a reduction in $\mathrm{CO} 2$ emissions ${ }^{2}$. Kempton and Letendre (1997) present the opportunities created by EVs as power sources for electric utilities and the possibilities offered thanks to adequate controls for 'valley filling', limiting charging when the networks are overloaded, or discharging inside the grid when needed.

Numerous studies have evaluated the potential economic impacts of EVs in several OECD countries (Kempton and Tomić, 2005a, 2005b; Kintner-Meyer et al., 2007; Hadley, 2008). Perez et al. (2014) found that a public policy to promote EVs would entail significant social benefits. Parks et al. (2007) focused on a region of the USA and specified four penetration scenarios for EVs. Their results indicated that discharging at peak hours would be most efficient for the network operation, reducing both generation costs and $\mathrm{CO} 2$ emissions. However $\mathrm{SO} 2$ increased due to the use of coal as a source of generation during peak hours. Some studies were carried out in island systems like Samsoe in Denmark (Blyth, 2011), Prince Edward Island (McCarville, 2009) and San Miguel in the Azores (Camus et al., 2012). The last-mentioned authors pointed out that the introduction of EVs reduced emissions ofCO2, increased the use of renewable energy and reduced both the costs of electricity generation and external dependence. However, as these authors remark, the results of the introduction of EV's obtained in one place may not be valid in another where the technical and geographical settings can be very different.

In this research we want to analyse the impact of introducing a large fleet of electric cars on the cost and risks of the Canary Islands' electricity mix. The battery-powered vehicles could be considered as distributed storage systems available for vehicle-to-grid services to help grid balancing. The starting point for our empirical analysis was taken from Marrero and Ramos-Real (2010). That paper assesses the situation and the energy objectives proposed in PECAN (2006) for electricity generation, taking into account the average cost and the risk associated with the different alternatives for generating electricity by means of the mean-variance portfolio theory (MVPT) (Markowitz, 1952; Luenberger, 1998). Marrero and Ramos-Real (2010) highlight two major issues: first, the enormous current inefficiency in generating electricity in the Islands; second, the important gains in terms of average cost, cost volatility (risk) and $\mathrm{CO} 2$ emissions in shifting towards an efficient system which involves optimising the use of renewables (mainly wind and PV) as a complement to the introduction of natural gas to generate electricity. In this framework, we will include a large fleet of EVs and the resulting effect on the power system in terms of costs and risk. MVPT is a useful frame to analyse this introduction of an EV fleet because it exploits the benefits of diversification between alternative technologies in order to reduce the level of risk of the electricity-generating portfolio, which is higher in such isolated systems than in an interconnected economy ${ }^{3}$. 
The paper is organised as follows. Section 2 reviews some of the basics of electric power systems to identify potential contributions of the EV fleet. Section 3 shows the theoretical framework and methodology. Section 4 describes the data, the hypothesis and the technical restrictions that determine the hypothetical penetration scenario of EVs. In Section 5, the estimation of the energy efficiency frontiers for both total risk and systematic risk is estimated and discussed. The last section provides conclusions.

\section{Basic characteristics of electric power systems and potential EV fleet contributions}

As electricity is a non-material product, it needs an infrastructure to be delivered to consumers: the electrical grid that links power plants to consumers through transformers and overhead or cabled lines. At the beginning of the 20th century, every country chose alternative current technology since it made possible - thanks to a key device (the transformer) - the transmission of high power at high voltages and reduced losses. In the actual context of emissions reduction worldwide, objectives have been given for cleaner energies and increased energy efficiency ${ }^{4}$. To meet these challenges, we will first recall the generic technical organisation of power systems including networks, generation mix and power system security (2-1); then we will present the challenges introduced by electricity market reform and how power systems can benefit from adapted rules to the development of EV fleets (2-2).

\subsection{Networks, generation mix and power system security}

The electric power networks are divided into two parts: the transmission grid and the distribution grid. The former links the centralised power plants to the largest consumers and to large substations that feed the distribution grids. The transmission grid has a meshed topology to maintain the continuity of service and to increase system stability in the event of line tripping ${ }^{5}$. The transformers' substations step down the voltage to feed the distribution grid at medium voltage level and then distribution transformers deliver the low voltage to small customers. To this end, the grid has been built with a mainly radial topology to make it easier and cheaper to operate ${ }^{6}$. One industrial characteristic of an electrical network is the long lifespan of equipment (several decades) and their large sunk cost. Thus any innovation must be carefully analysed with regard to their impact on system security, on the complementary investments required (or those to be avoided) and the impact on actual and future operational costs.

The generation mix of electricity depends on available resources and strategic choices in a given region. For example, France chose nuclear generation in the 1970's to ensure its energy independence, Norway has a 95\% hydro mix due to its resources and Poland has a $90 \%$ coal generation portfolio. The generation mix is divided into three main categories $^{7}$ : base-load plants (nuclear, run-of-river hydro), semi-base load plants (coal and gas turbines) and peak load plants (gas or oil combustion turbines) ${ }^{8}$. To meet the different levels of demand in the year, from the minimum on Saturday summer nights to the maximum in wintertime working days, a combination of the different technologies is required where electrical storage is not widely developed. Electricity is an uncommon product in the sense that it is a non-material form of energy and thus it can only be easily and economically stored through a process of transformation ${ }^{9}$. 
During the second part of the 20th century generation capacities were built up through large vertically integrated companies under public regulation which were favourable to centralised plants connected to high voltage grids ( $400 \mathrm{kV}$ or more): from $100 \mathrm{MW}$ for a single hydro plant to $1,450 \mathrm{MW}$ for a single nuclear reactor. Each generation's technology has its own dynamic performances that characterises its flexibility: start-up and shut-down costs and durations, ramping limits (MW/s) to increase or decrease the operating point, minimum value of the operating point. Power plant flexibility is critical for the safe operation of the power system because the generation must continuously balance the demand in order to keep the frequency around its rated value $\left(50 \mathrm{~Hz}\right.$ in Europe, $60 \mathrm{~Hz}$ in the USA) and to prevent blackouts ${ }^{10}$. The optimal generation plan depends on plants' marginal costs, their flexibility and demand profile ${ }^{11}$.

Finally, electric power system security is based on three criteria: the need for frequency control operations, the need of voltage control and finally the efficient management of congested lines (Codani et al., 2014a, 2014b).

- Why and what is the power system frequency control requirement?

For an AC system, a single value of the frequency is measured whatever node is inside the grid. This frequency is linked to the generator's speed and its variation is an image of any imbalance between generation and demand: the rotating parts of the generator behave as a storage system with an increase or decrease in kinetic energy. Then, to keep the frequency very close to $50 \mathrm{~Hz}$, the mechanical power delivered by the turbines is controlled to follow demand. As demand always changes according to the day, the week and the month, some power plants must be flexible enough to supply a power reserve that must be available at very short notice (from a few seconds to a few minutes). So in case of a large disparity in generation, the grid operator may need additional power in reserve to ensure the balance in real time ${ }^{12}$.

- Why and what is the power system security voltage control requirement?

The second key parameter of electric power system security is the voltage level at each node of the grid. The grid operators must keep the voltage within a certain range to ensure a good quality of power for their customers. In a transmission system, the generators mainly control the voltage. In radial distribution networks, the load level and line length have a strong impact on the voltage control quality and delivery.

- Why and what is efficient congestion management needed in electricity grids?

Lastly, all power equipment (lines, cables, transformers, etc.) are sized for a maximum rate of current. Overloads will have a strong impact in terms of network costs ${ }^{13}$ and, if they are not managed, they will even lead to electrical blackouts for the entire power system. Thus there are real incentives for network operators to take care to prevent any overload $^{14}$.

\subsection{The challenge of market liberalisation and the EV fleet contribution}

The liberalisation process in energy markets has two complementary faces: first, governments have introduced a new economic framework and with the help of national regulators they have tried to split up their vertically integrated electricity companies into a bunch of new companies, some being regulated and some created to pursue market-based activities (Glachant and Perez, 2009). The introduction of 'markets 
where possible' has led governments to perform industrial surgeries and to insulate the generation and retail business around new competitive practices, while at the same time setting the boundaries of this reform by defining the natural monopoly activities of transmission and distribution networks (Glachant and Perez, 2009). Thus, these natural monopolies need to be regulated to allow all the network users to be treated fairly according to their constraints, opportunities and contributions. The liberalisation process initiated in 1996 in Europe $^{15}$ is an ongoing process around the world. The quest for a perfect definition of this combination of new market activities and the regulation associated with them is still an ongoing process (Perez and Ramos-Real, 2008; Glachant and Perez, 2009; de Hautecloque and Perez, 2012).

The second face of this process of liberalisation is the political will to open the generation mix to new $\mathrm{CO} 2$-free generation units via different public support mechanisms ${ }^{16}$. As a consequence, new investors and new technologies have been incentivised and introduced in liberalised energy markets to meet the challenge of pollution reduction targets via the intensive use of renewable sources for generating green electricity. In the last ten years, CO2-free sources for generating electricity like mini hydro $^{17}$, onshore and offshore wind, photovoltaic (PV) and biomass have been developed. These new plants have been designed and installed in electricity networks and they are being used more and more frequently.

As a matter of fact, we are entering a new energy paradigm, which was ushered in by the rapid development of distributed small generation units (less than $10 \mathrm{MW}$ and down to $3 \mathrm{~kW}$ for a single unit) connected to the distribution grids. This new situation creates risks and opportunities for grid managers and forces them to investigate new possible sources of network service provision for frequency, voltage and congestion and to think of how to change the rules to allow the development of these innovations in a safe way.

- What are the new problems introduced by the development of distributed generation?

Despite their ecological advantage, the drawbacks of these renewable energy sources in the generation of electricity are their unpredictability, their intermittency ${ }^{18}$, the increase of technical difficulties they create for other generators, forcing them to provide an adequate level of power and energy to meet the needs of network users (the so-called intermittency $\operatorname{cost}^{19}$ ) and finally the creation of more complex forecast of net electricity demand of final consumers ${ }^{20}$.

In this context, EV fleets can be part of the solution to the challenge of renewable energy source integration in the provision of the required network services. In the context of harsher constraints for $\mathrm{CO} 2$ emissions, automakers and their suppliers have optimised their engines with innovations such as 'start\&stop startergenerator', kinetic energy recovery systems, hybrid systems, full-battery EVs and plug-in hybrid vehicles. In the last two cases, the energy stored in the batteries will totally or partially come from the electric grid and then reduce the car $\mathrm{CO} 2$ emission accordingly. But more than just being cleaner by consuming electricity instead of diesel or gasoline, EV fleets are also capable of providing some power and energy to the electrical grids. This provision is potentially a valuable contribution of EV fleets to the power system ${ }^{21}$. Here we will evaluate the benefits introduced by a large EV fleet in a small and isolated electrical system because we do think they are suitable target for innovation due to their favourable performance under strict technical and economic constraints (Rious and Perez, 2014; Weisser, 2004). Isolated systems can only accommodate a very limited capacity of power from renewable energy sources. Indeed, beyond a certain amount of intermittent renewable power, it is 
not possible to reduce the generation coming from some conventional thermal plants in order to balance generation and load. It is important to understand that conventional thermal power plants are used to provide the necessary reserve margin to balance the power system instantaneously, whereas renewable are not (Bayem, 2009). This technical constraint limits the integration of more renewable energy in island power systems and makes it more difficult to achieve objectives of energy independence and reduction of greenhouse gas (GHG) emissions.

\section{Evaluation methodology of the EV fleet contribution by MVPT}

As noted in Awerbuch (2000) most research on investment and planning decisions in the energy industry is aimed at an individual study of the costs of the various technological options for generating electricity (stand-alone generating costs) and on minimising these costs. The MVPT approach, however, relegates to the background two particularly relevant issues. First, not only should the average cost of each alternative be considered, but also the associated risk, measured in terms of uncertain cost fluctuations. Second, the relevant exercise is not a stand-alone analysis, but the joint analysis of all the technological options of a so-called electricity generating portfolio (or mix). By maximising a social welfare function, the energy portfolio is characterised by a set of weightings, each between zero and one, of all feasible energy alternatives. Those weightings, say $X_{1}, \ldots X_{n}$, must add up to unity and are subject to certain technological restrictions that determine the range of variation of each energy source in the portfolio under alternative scenarios. For instance, depending on whether we consider the short or the long run, different technical restrictions can be assumed. Such restrictions are discussed in the next section ${ }^{22}$.

The average cost of the energy portfolio is defined as the weighted average of the various individual costs according to those weights:

$$
\overline{C C}=\sum_{i=1}^{n} X_{i} \cdot \overline{C_{i}}
$$

It is clear from this expression that, given the technological restrictions, the minimum average cost of the fuel mix will correspond to a combination of the least expensive technologies. The MVPT approach combines the information on restricted average costs above, with the risk costs associated with each feasible portfolio. If we consider a traditional approach, measuring risk involves the volatility of historical data: the greater the individual cost's volatility, the greater the uncertainty and the associated risk. In the case of a single technology, its risk can be calculated by using a measure of its cost dispersion (i.e., the standard deviation). However, when estimating the electricity portfolio risk, it is also necessary to consider the cross-correlation costs among all the different technologies. Once the average cost and risks of all feasible generating portfolios are determined, an efficient mix minimises the volatility, for a given level of average cost and over every feasible combination, given technological restrictions. The set of all efficient energy portfolios comprises what is known as the energy efficient frontier (EEF).

Figure 1 illustrates a hypothetical EEF. The average cost is along the y-axis and the measure of risk along the $\mathrm{x}$-axis. 
The minimum cost (MC) mix includes the cheapest technologies, given technological restrictions. Starting from this mix, moving left along the frontier, more diversified portfolios would presumably increase the average cost while, simultaneously, reducing the variance until the minimum variance (MV) mix is reached. Given positive correlations among the different alternatives, as is generally the case for energy, the more concave the frontier, the greater the possibility of reducing risk by diversification. As we will see in Section 4, this issue is important when distinguish between total and systematic risk. Being to the left of the frontier would be unfeasible, while any portfolio above the MV or to the right of the frontier would be inefficient. In order to use a benchmark efficient mix, we can consider the one in the mean of the MC and the MV portfolio, i.e., the MC-MV mix. The estimated frontier also allows us to assess specific portfolios and to offer directions for improvement. Suppose, for instance, that we wish to assess portfolio A, which is clearly inefficient. We can define two portfolios, B and C, of particular interest with respect to the reference portfolio A. Portfolio B involves the same level of risk as the reference one, but with lower cost by virtue of being on the frontier, while portfolio $\mathrm{C}$ has the same cost as the initial one and involves moving to the frontier by reducing risk. In reality, any mix between portfolio $B$ and $C$, like portfolio $D$ in the figure, will be more efficient than the reference mix, since it would improve in both dimensions with respect to $\mathrm{A}$.

Figure 1 EEF: an example (see online version for colours)

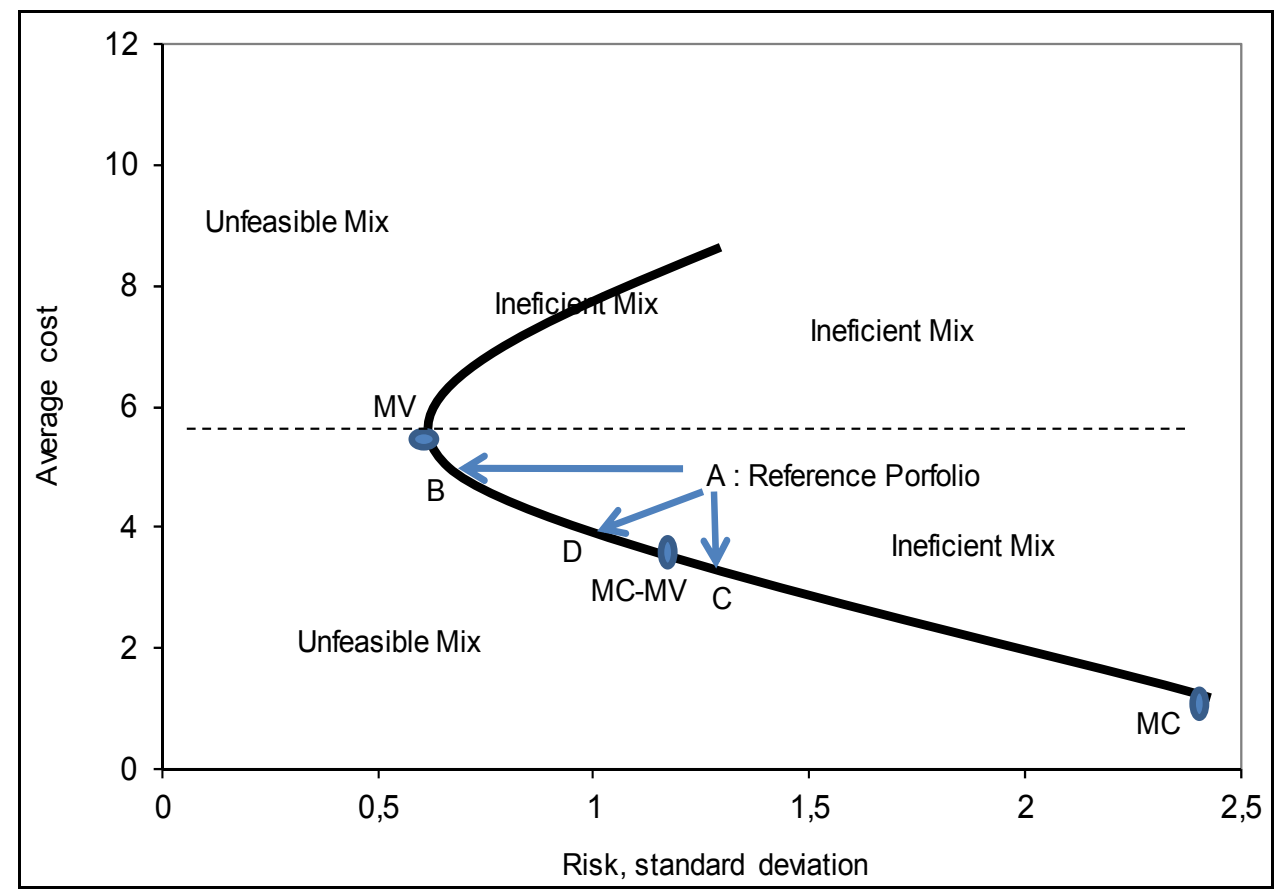

Source: Based on Marrero and Ramos-Real (2010) 
Table 1 Canary Islands' electricity data

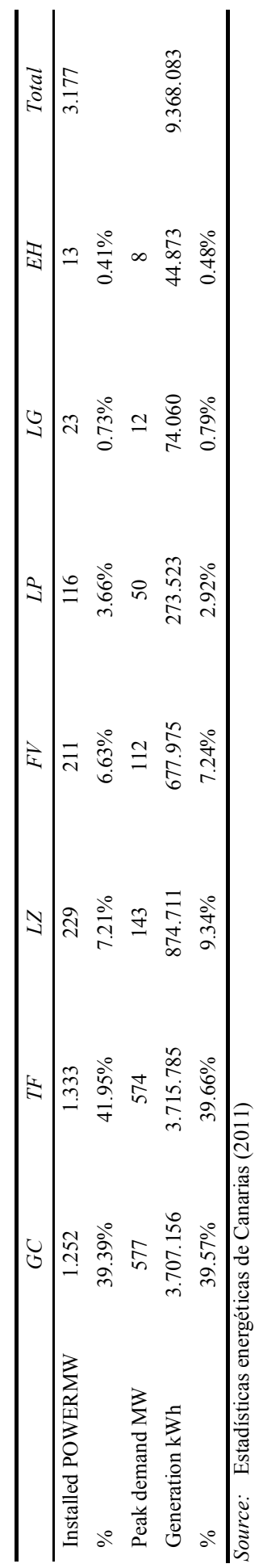




\section{The Canary Island electricity system}

The Canary Island electricity system presents the characteristics of an isolated system; that is, it is not connected to the major European electricity networks. Moreover, the isolation of the system is twofold since each island in turn forms an independent electricity grid, with the exception of the connection between Fuerteventura and Lanzarote. Electricity generation in the Canary Islands in 2011 was 9,368 GWh (about $3.5 \%$ of national consumption). Table 1 shows electricity generation, installed power and peak demands in the seven islands, which gives us an idea of the size and importance of each power system. Renewable energies accounted for only $6.4 \%$ of the electricity generation in 2011, primarily due to the contribution of wind and PV energy. In Spain, renewable energies account for nearly $20 \%$ of the electricity generated (excepting hydroelectric). The remainder of the islands' generation comes from oil derivatives. The fragmentation into small sub-systems essentially means that only oil-fired power stations have been used as a source of electricity generation. The two largest islands are comparable with the EU's main isolated systems in terms of installed capacity, demand profile and size and levels of voltage grids.

\subsection{Electricity generating costs in the Canaries}

As previously mentioned, we will use the estimations of Marrero and Ramos-Real (2010) calculated by the levelised cost of electricity (LCOE) method. This method calculates the costs over the electric plants' useful lifetimes and averages them out to yield a total production cost. Moreover, a probabilistic analysis similar to that used in Feretic and Tomsic (2005) was used. The details of the methodology used in this probabilistic analysis, as well as the specific values for the various parameters used in our calculations, are shown in Marrero and Ramos-Real (2010).

The generating costs can be divided into investment, production and operation and maintenance costs; other significant costs are emissions costs (imputed to fossil technologies) and interruption costs, which are imputed to renewables with a sizable market share. These costs have been estimated by using the relationship that exists between them and a set of key parameters for which data are available and whose values depend on each technology (see the Appendix in Marrero and Ramos-Real (2010) for more details about this point). Among these parameters, a relevant one is the capacity or load factor, which basically refers to the feasible time of use of the different technologies. To obtain the results (the average and the percentiles) in Table 2, we have used a capacity factor of about 80-85 for natural gas, fuel oil and diesel oil technologies, of 30-35 for wind and of 25-30 for PV. Thus, whenever we change the range of any parameter affecting the average cost (for example, an increase of the load factor or a reduction of the intermittency cost, as will be done in Section 5), we recalculate the LLC of the affected technology (wind and PV in or case) and, depending on the new average costs, a new efficient frontier and efficient portfolios (MC, MV and MC-MV) are characterised. 
Table 2 Electricity generation costs in the Canaries (euro-cents/kWh) ${ }^{(*)}$

\begin{tabular}{lcccccc}
\hline & CCgas & Diesel & Fuel 'old' & $\begin{array}{c}\text { Wind } \\
\text { (on-shore) }\end{array}$ & PV & $\begin{array}{c}\text { Fuel } \\
\text { 'new }\end{array}$ \\
\hline Average & 7.34 & 18.59 & 13.57 & 7.16 & 13.54 & 11.48 \\
95th percentile & 8.58 & 22.41 & 16.20 & 8.14 & 15.94 & 13.61 \\
Fifth percentile & 6.27 & 15.47 & 11.37 & 6.22 & 11.21 & 9.61 \\
\hline
\end{tabular}

Notes: ${ }^{(*)}$ Probabilistic estimate of levelised bus-bar cost; 5,000 Monte Carlo simulations, Costs include market costs of $\mathrm{CO}_{2}$ emissions and for wind farms, the intermittency cost,

${ }^{(1)}$ This technology assumes the same efficiency factor as CC diesel or gas plants Source: Marrero and Ramos-Real (2010)

The generating options considered include the main technologies currently used in the Canaries, which are fuel-oil, diesel, on-shore wind and PV plants. The only feasible alternative in the short term in the Canaries is offered by combined cycle natural gas plants $^{23}$. So as not to bias the comparison with current fuel plants (fuel-old) in favour of new combined cycle natural gas plants, we also consider the possibility of using fuel-oil plants (fuel-new) which are as efficient as those of natural gas. Table 2 shows the average value and the fitth and 95th percentiles. The cheapest generating cost is for the natural gas technology and is around 7.34 euro-cents $/ \mathrm{kWh}(90 \%$ probability of being in the $6.27-$ 8.58 euro-cents/kWh range). The range for current fuel-oil plants is between 11.37 and 16.20 , the average being slightly over 13 euro-cents $/ \mathrm{kWh}$. Note that the 95 th percentile for combined cycle gas plants is far below the fifth percentile for current fuel plants. The same is true for the fuel-new plants, though their cost would be between 9.6 and 13.6 euro-cents/kWh. The most expensive generating alternative is for diesel plants, whose cost ranges from 15.6 to 22.4 euro-cents/kWh, the average cost being 18.59. As for renewables, wind energy is the only technology in the Canaries whose costs approach those of a combined cycle gas plant. Its cost would range from 6.22 and 8.14 euro-cents/kWh, with an average cost of 7.16 . Finally, the generation costs for PV vary between 11 and 16 euro-cents, with the average being 13.5, just below that of diesel plants. We should note that intermittency costs were taken into account for wind power but not for PV, since we assume the PV share will not exceed $10 \%$.

\subsection{EV's penetration scenarios and hypothesis}

In this paper we investigate the potential of EV's to support a penetration of renewable electricity generation inthe Canary Islands. Dedicated aggregators can manage services provided by an EV fleet ${ }^{24}$. Although the services that EV's can offer are broader, in this study, we focus on the following effects: a higher penetration share of renewable energy in the generation mix (specifically wind), a reduction in the use of diesel turbines for generating electricity in the smallest islands and a reduction in intermittency costs for renewables, thanks to the storage capabilities of $\mathrm{EV}^{25}$.

\subsubsection{EV: potential impacts on the electricity mix}

The most common EV charging plug is $3 \mathrm{~kW}$ and average capacity of the battery is $24 \mathrm{kWh}$. Moreover, we assume a maximum driving range of $150 \mathrm{~km}$ and a rate of use of 
EV cars between $20 \%$ and $40 \%$ of the battery charging capacity per day ${ }^{26}$. Accordingly, the charging time of the battery with a simple $3 \mathrm{~kW}$ plug will be between 1:30 to 4 hours. Moreover the vehicles are mainly parked during the day: if we consider a two hour round-trip between home and the office, the vehicles could stay connected to the grid for 22 hours either at home or at the office. Thus, battery vehicles could be considered as distributed storage systems available for vehicle-to-grid services to help grid balancing. The idea is to evaluate the benefits and risks of the introduction of an EV fleet of a maximum of 122,000 cars into the Canarias market in 2025. From these data, the following facts emerge: first, 50,000 cars in Tenerife or Gran Canaria represent about $10 \%$ of existing cars (residential cars) on each island and $12 \%$ of the electricity generated. Second, the same percentage of energy could be generated by 500 cars in El Hierro, 1,000 cars in La Gomera, 3,500 cars in La Palma, 7,000 in Fuerteventura and 10,000 in Lanzarote. Third, EVs could supply about $9-11 \%$ of the power installed in each island. To summariSe, 122,000 cars could generate about $12 \%$ of the electricity in the archipelago in $2025^{27}$.

\subsubsection{Technical restrictions}

In the absence of $\mathrm{EV}$ penetration, the following restrictions should be considered.

As we showed in (1), an electricity-generating portfolio is represented by the set of all the weights of the different electricity-generating technologies. In our case, $X_{1}$ is the percentage supplied by CC gas plants, $X_{2}$ by diesel, $X_{3}$ by 'old-fuel' oil plants, $X_{4}$ by on-shore wind, $X_{5}$ by PV and $X_{6}$ by 'new fuel' oil plants. These weights must always add up to unity and are subject to certain technical restrictions. While the weights $X_{1}, X_{3}$ and $X_{6}$ could range, in principle, from zero to one, $X_{2}$ has a lower limit of 0.15 due to the need to use these plants on small islands, while those for wind and PV have upper limits of 0.25 and 0.05 , respectively, to ensure the security and stability of the electricity supply due to the isolation of the electricity grids on the islands and the problem of the intermittency of these technologies ${ }^{28}$.

Considering the penetration of $122,000 \mathrm{EVs}$, we can assume that the upper limit for wind and PV could reach $33 \%$ and $7 \%$ respectively ${ }^{29}$. A maximum of $30 \%$ by 2015 is specified for wind and solar in PECAN (2006), but there is already talk in the Government of the Canaries of $40 \%$ between both technologies in the longer term. On the other hand, we could reduce from $15 \%$ to $10 \%$ the lower limit for diesel plants to meet demand in smallest islands. Finally, these two restrictions have two effects on the costs of renewables. First, we can increase the load factor of wind (from 35 to 40). Second, a one-third reduction in the intermittency costs of renewables may be considered ${ }^{30}$.

\subsection{Defining different risk scenarios}

The risk scenario we have used is also based on Marrero and Ramos-Real (2010). These authors describe reasonable scenarios for the risk structures of the alternative technologies considered and conclude that main results are quite robust to the chosen scenario. We use in this paper the fourth scenario, which they call eclectic. This scenario may be viewed as an intermediate and more realistic situation based on alternative scenarios. Here, the individual volatility among the fossil technologies is the same (1.29); the volatility for renewables is positive but lower (0.65, approximately half); the cost correlation among fossil fuels is 0.95 between diesel and fuel oil and somewhat lower 
when compared to gas (0.87); the correlation between renewables is positive, but smaller (0.5); finally, the correlation between fossil fuels and renewables is also positive, but the smallest of all (0.25). As in Marrero and Ramos-Real (2010), minor sensitivity analyses conducted for this scenario did not yield any significant changes in the results.

\section{The efficient frontier: an assessment of the current situation in the Canaries and of the PECAN proposal}

We calculate the efficiency frontier for the electricity system in the Canaries in terms of both average cost and risk under alternative energy scenarios. Our analysis is based on the hypothesis and restrictions assumed in the previous section. In the baseline scenario we assume no penetration of EVs, hence we present an estimation of the current EEF. Second, following the assumptions made in Section 3, we consider an increase in the maximum allowed penetration of wind, from the $25 \%$ assumed in the baseline to approximately $33 \%$ and from 5 to $7 \%$ for PV. At the same time we lower the minimum limit of diesel from $15 \%$ to $10 \%$. The third scenario, for wind technology, considers that its load factor increases from the baseline $30-35 \%$ to about $40-45 \%$, while at the same time the intermittency cost is reduced to about one third from the baseline.

The fuel portfolio is composed of the set of weightings $\left(X_{1}, X_{2}, X_{3}, X_{4}, X_{5}, X_{6}\right)$, which add up to one and are subject to the technical restrictions discussed in Section 3. The average cost of the electricity mix is computed from equation (1).Once the average cost and risk of an electricity mix are determined, the EEF is computed from the set of all efficient portfolios ${ }^{31}$. Figure 2 depicts the estimated EEF for the baseline situation. As a reference mix for the frontier, we consider a representative mix (measured for the 2008-2011 period): $71 \%$ fuel-oil, $22 \%$ diesel, $6 \%$ wind and $1 \% \mathrm{PV}$. We highlight in the figure the 'MCs' the 'equal risk than the reference (ECR)' the 'MV' and the 'MC-MV (average between MC and MV)' efficiency portfolios that result from our mean-variance approach. Detailed results for these specific efficient portfolios (the weights for each technology, as well as the average cost, the associated volatility and a measure of $\mathrm{CO} 2$ emissions) are shown in Table 3.

Following Marrero and Ramos-Real (2010), we first highlight the significant inefficiency of the current electricity mix in the Canary Islands, highly concentrated on diesel and fuel. In comparison with an alternative combination of gas-renewables, these two technologies show high average cost, high variances and strongly positive correlation (almost 1), hence their combination basically does not reduce the risk in the overall mix (Figure 2). As a result, the current electricity-generating portfolio is far away from the $\mathrm{EEF}$ in the two dimensions (mean and variance). It is also inefficient from the point of view of $\mathrm{CO} 2$ emissions. As is shown in Table 3, the MV portfolio gives a maximum share to renewables: $25 \%$ of wind and $5 \%$ of PV. The remaining $70 \%$ is diversified as much as possible among the alternative fossil technologies: natural gas, diesel and fuel. At the other extreme of the frontier, the MC mix concentrates on the cheapest technologies (natural gas and to a lesser extend wind), given the minimum requirement of $15 \%$ of diesel. 
Figure 2 Efficient electricity generating frontier in the canaries: baseline scenario (lack of penetration of EVs) (see online version for colours)

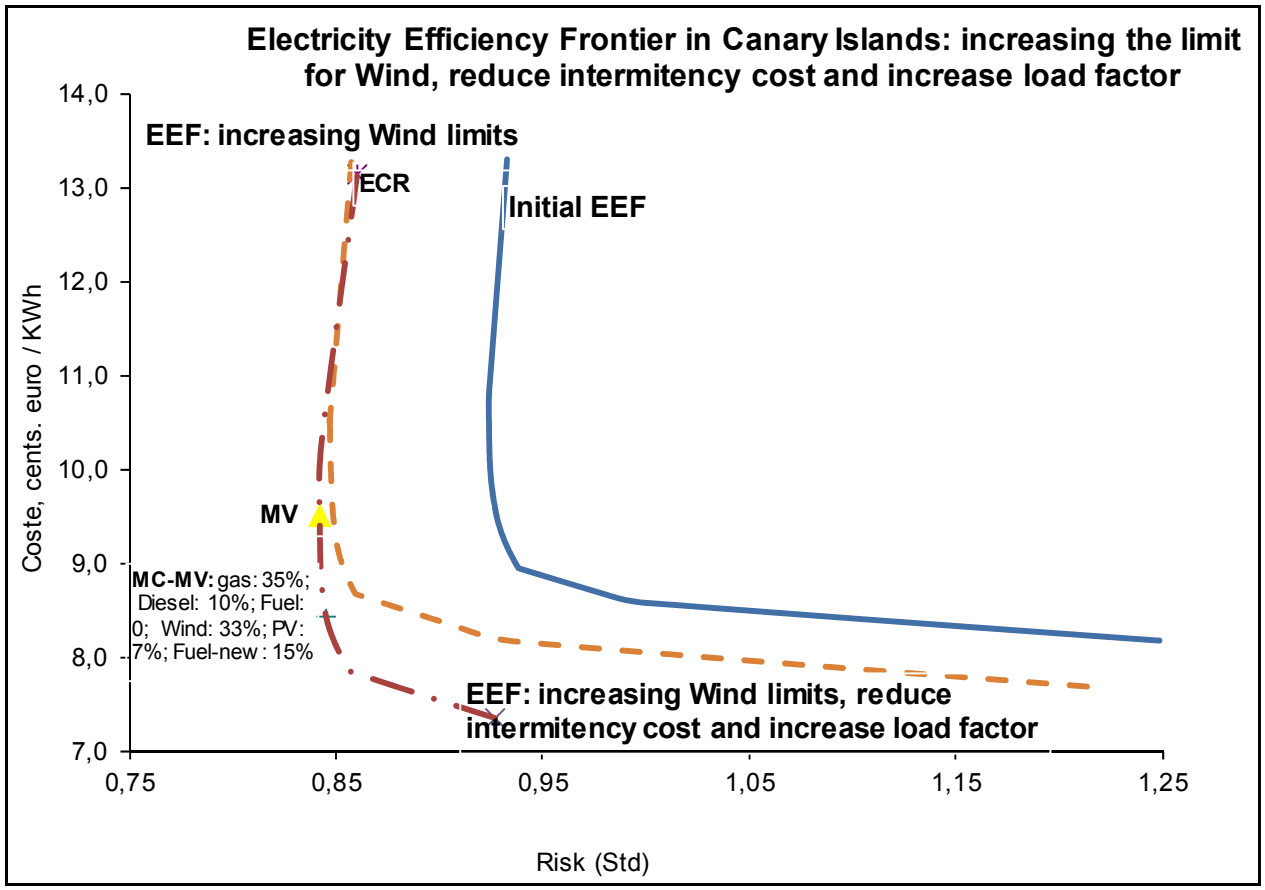

Table 3 Efficient electricity portfolios in Canaries under the baseline scenario (lack of penetration of EVs)

\begin{tabular}{lccccc}
\hline & $\begin{array}{c}\text { Reference } \\
\text { portfolio, } \\
\text { Canary } \\
2008-2011\end{array}$ & $\begin{array}{c}\text { Minimum } \\
\text { risk }(M V)\end{array}$ & $\begin{array}{c}\text { Minimum } \\
\text { cost }(M C)\end{array}$ & $\begin{array}{c}\text { Equal cost } \\
\text { than } \\
\text { reference } \\
\text { (ECR) }\end{array}$ & $\begin{array}{c}\text { Average } \\
\text { between } \\
\text { MV-MC }\end{array}$ \\
\hline Cost (cents euro/kWh) & 13.30 & 10.68 & 8.17 & 13.30 & 9.43 \\
Risk, std & 1.20 & 0.92 & 1.25 & 0.93 & 0.93 \\
CO2, TM/kWh. & 0.55 & 0.37 & 0.46 & 0.37 & 0.35 \\
Gas & 0.0 & 28.6 & 83.4 & 15.4 & 42.2 \\
Diesel & 22.0 & 22.1 & 15.0 & 54.6 & 15.0 \\
Fuel-oil (old) & 71.0 & 10.8 & 0.0 & 0.0 & 0.0 \\
Wind & 6.0 & 25.0 & 1.6 & 25.0 & 25.0 \\
PV & 1.0 & 5.0 & 0.0 & 5.0 & 5.0 \\
Fuel-oil (new) & 0.0 & 8.5 & 0.0 & 0.0 & 12.8 \\
\hline
\end{tabular}

We will use the average mix between the MC and the MV portfolio (the MC-MV mix) to make comparisons between the alternative scenarios. In the baseline setting, this MC-MV mix is represented by $42 \%$ of gas, $15 \%$ of diesel (the minimum), $25 \%$ of wind (the maximum), $5 \%$ of PV (the maximum) and $13 \%$ of fuel-oil (but using the new technology, which is more efficient than the old one). It is worth noting that this mix is similar to the one proposed in PECAN $(2006)^{32}$. In comparison with the current portfolio, moving to 
the MC-MV mix assumes a gain in all dimensions: a reduction of $29 \%$ in average cost, $22 \%$ in risk and $36 \%$ in $\mathrm{CO} 2$ emissions.

\subsection{The EV's penetration scenarios}

The next scenario we show assumes an EV penetration of 122,000 cars. This would affect our mean-variance portfolio analysis by increasing the maximum degree of penetration of wind and reducing the minimum share of diesel. Figure 3 and Table 4 shows the results of this alternative scenario. In the Figure, we compare the EEF under the baseline and under the new scenario. It is worth noting that the EEF under the new scenario is clearly to the left of the baseline one, which implies that further reductions in average cost and risk in the generation of electricity can be achieved if EVs are introduced.

The MC-MV under the new scenario is: $37 \%$ gas, $10 \%$ diesel, $13 \%$ fuel-oil (new), $33 \%$ wind and $7 \%$ PV (the maximum allowed $40 \%$ for renewables). Basically, renewables (wind and $\mathrm{PV}$ ) have increased in the mix against the fossil alternatives, especially natural gas, whose share now falls from $42 \%$ to $37 \%$; diesel is set to its new minimum, $10 \%$, while fuel-oil (under the new, more efficient, technology) remains in the mix with almost $13 \%$. Comparing the MC-MV mix of both EEFs, the one in the new scenario supposes a reduction of another $3 \%$ in average cost, a reduction of $8.4 \%$ in risk and one of $14.3 \%$ in $\mathrm{CO} 2$ emissions.

Figure 3 Efficient electricity generating frontier in canaries: baseline and scenario 1 (penetration of EVs with increase in maximum share of wind) (see online version for colours)

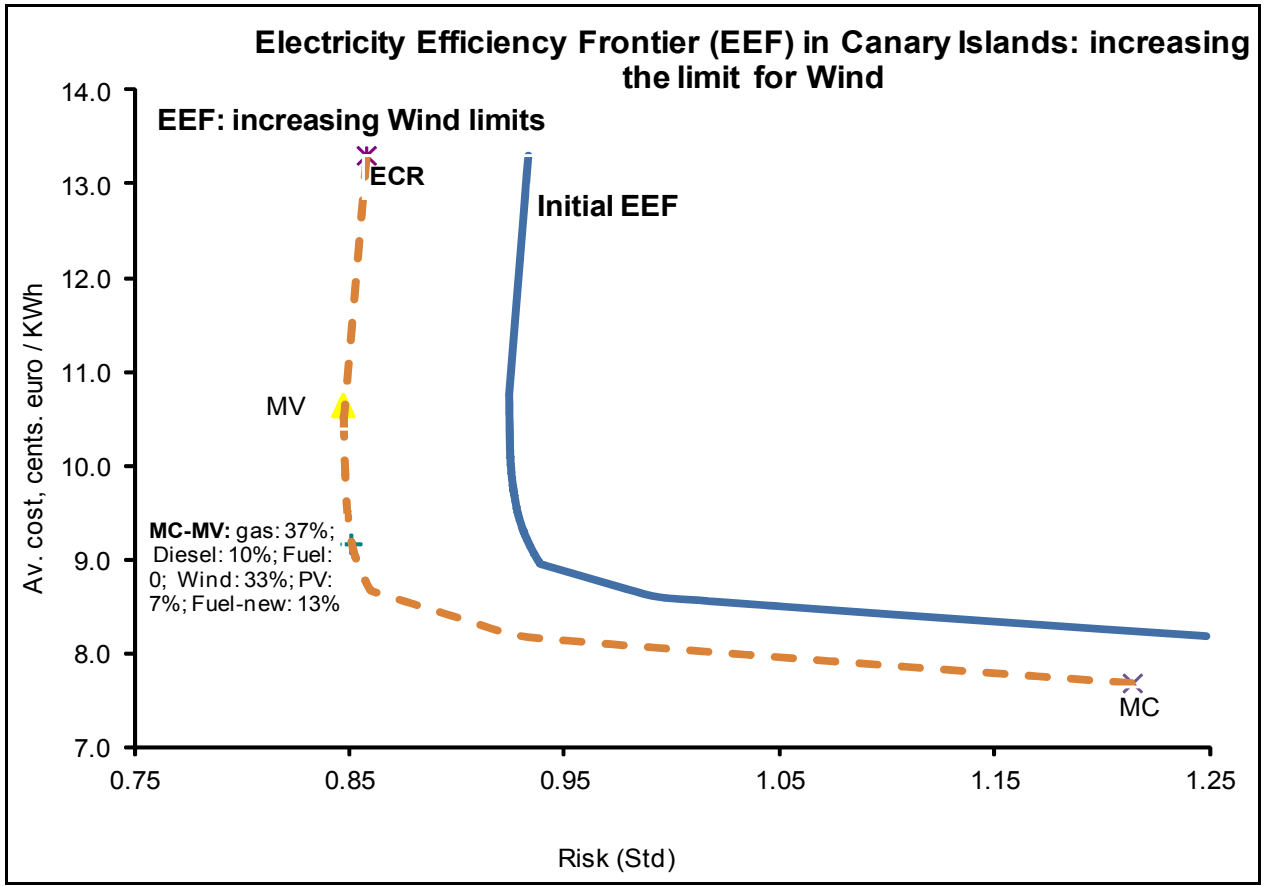


Table 4 Efficient electricity portfolios in the Canaries underpenetration of EVs with increase in maximum share of wind

\begin{tabular}{lccccc}
\hline & $\begin{array}{c}\text { Reference } \\
\text { portfolio, } \\
\text { Canary } \\
\text { 2008-2011 }\end{array}$ & $\begin{array}{c}\text { Minimum } \\
\text { risk }(M V)\end{array}$ & $\begin{array}{c}\text { Minimum } \\
\text { cost }(M C)\end{array}$ & $\begin{array}{c}\text { Equal cost } \\
\text { than } \\
\text { reference } \\
\text { (ECR) }\end{array}$ & $\begin{array}{c}\text { Average } \\
\text { between } \\
\text { MV-MC }\end{array}$ \\
\hline Cost (cents euro/kWh) & 13.31 & 10.63 & 7.68 & 13.31 & 9.16 \\
Risk, std & 1.20 & 0.85 & 1.21 & 0.86 & 0.85 \\
CO2, TM/kWh. & 0.55 & 0.31 & 0.44 & 0.32 & 0.30 \\
Gas & 0.0 & 25.8 & 84.5 & 8.0 & 37.1 \\
Diesel & 22.0 & 22.3 & 10.0 & 52.0 & 10.0 \\
Fuel-oil (old) & 71.0 & 7.2 & 0.0 & 0.0 & 0.0 \\
Wind & 6.0 & 33.0 & 5.5 & 33.0 & 33.0 \\
PV & 1.0 & 7.0 & 0.0 & 7.0 & 7.0 \\
Fuel-oil (new) & 0.0 & 4.7 & 0.0 & 0.0 & 12.9 \\
\hline
\end{tabular}

Figure 4 Efficient electricity generating frontier in canaries: baseline, scenario 1 and scenario 2 (penetration of EVs with increase in maximum share of wind, its load factor and reduction of intermittency cost) (see online version for colours)

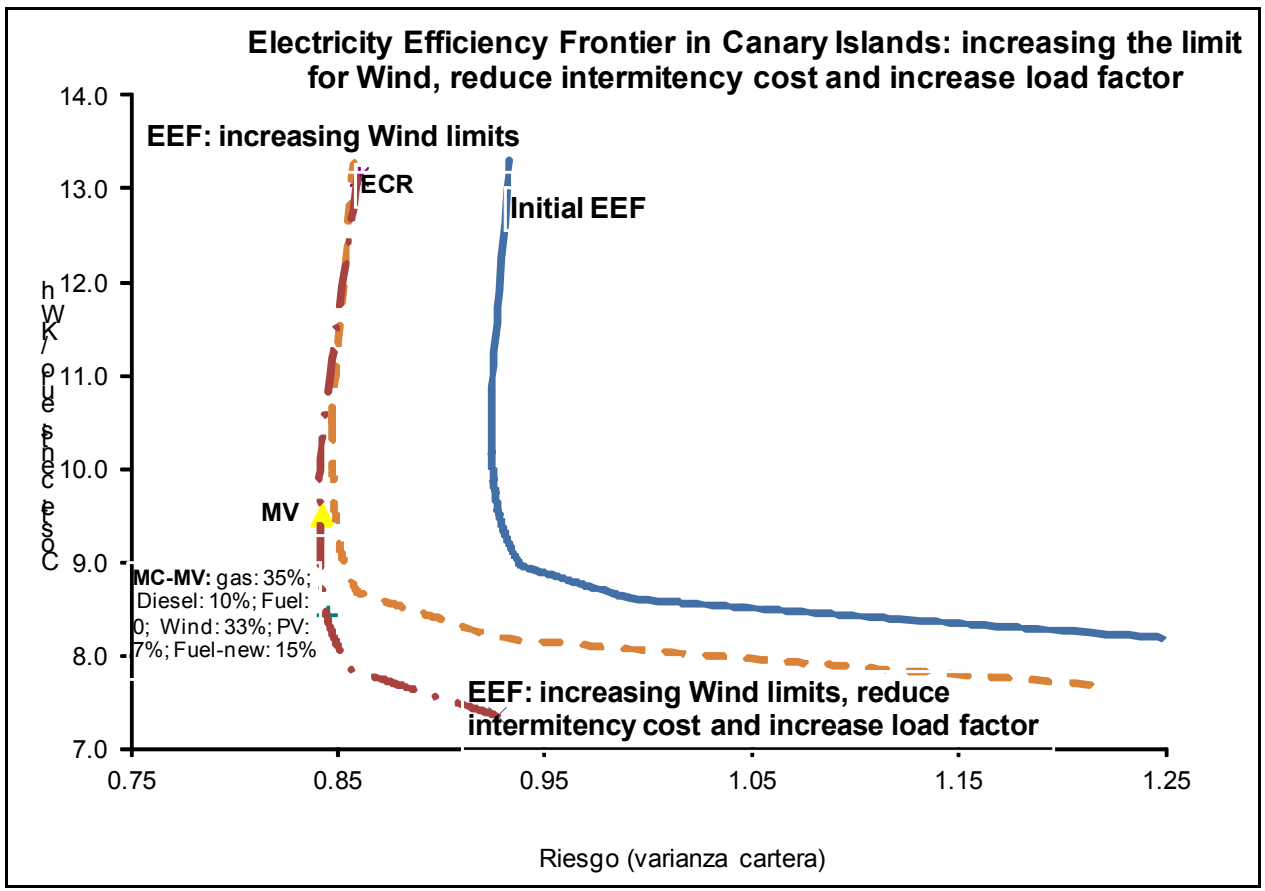

We add to the changes introduced in the second scenario the following possibilities: increase the load factor of wind and reduce its intermittency cost, which, as discussed in Section 3, would be the consequence of the penetration of EVs in the Canaries. Figure 4 and Table 5 summarise the results of this third scenario. First, since the maximum share of wind and PV was already binding under the previous scenario (with lower load factor 
and higher intermittency cost), the composition of the new MC-MV mix is basically the same as under the second scenario: $35 \%$ gas, $10 \%$ diesel, $33 \%$ wind, $7 \%$ PV and 15\% fuel-oil (new). The most important comparison is the following: the share of gas (cheaper) has been reduced in favour of fuel-oil (more expensive). Nevertheless, the comparison between the two MC-MV mixes supposes a reduction of almost $8 \%$ in average cost (basically because now wind is cheaper), but also a fall of $1 \%$ in risk, while $\mathrm{CO} 2$ emissions do not change.

This apparently counterintuitive result is possible because wind is now cheaper, hence we can increase the presence of a more expensive technology (such as fuel-oil) which is efficient because it allows an increase in diversification among the alternative fossil technologies without increasing the average cost. This result can be seen in Figure 4, which shows that the new frontier is to the left of that under the second scenario. The more efficient and cheaper wind and PV are the more diversification among the alternative fossil technologies is allowed in the EEF, which also benefits the reduction of risk at almost any level of average cost. Moreover, it is also worth noting that the MC mix is now represented by $33 \%$ wind and the remaining $77 \%$ is for diesel $(10 \%)$ and gas $(57 \%)$, while for the two previous scenarios the share of wind for the MC mix was basically zero.

Table 5 Efficient electricity portfolios in Canaries underpenetration of EVs with increase in maximum share of wind, its load factor and reduction of its intermittency cost

\begin{tabular}{lccccc}
\hline & $\begin{array}{c}\text { Reference } \\
\text { portfolio, } \\
\text { Canary } \\
2008-2011\end{array}$ & $\begin{array}{c}\text { Minimum } \\
\text { risk }(M V)\end{array}$ & $\begin{array}{c}\text { Minimum } \\
\text { cost }(M C)\end{array}$ & $\begin{array}{c}\text { Equal cost } \\
\text { than } \\
\text { reference } \\
\text { (ECR) }\end{array}$ & $\begin{array}{c}\text { Average } \\
\text { between } \\
\text { MV-MC }\end{array}$ \\
\hline Cost (cents euro/kWh) & 13.13 & 9.50 & 7.35 & 13.13 & 8.42 \\
Risk, std & 1.20 & 0.84 & 0.93 & 0.86 & 0.85 \\
CO2, TM/kWh. & 0.55 & 0.32 & 0.31 & 0.33 & 0.30 \\
Gas & 0.0 & 23.6 & 57.0 & 2.2 & 34.9 \\
Diesel & 22.0 & 16.4 & 10.0 & 57.8 & 10.0 \\
Fuel-oil (old) & 71.0 & 8.5 & 0.0 & 0.0 & 0.0 \\
Wind & 6.0 & 33.0 & 33.0 & 33.0 & 33.0 \\
PV & 1.0 & 7.0 & 0.0 & 7.0 & 7.0 \\
Fuel-oil (new) & 0.0 & 11.5 & 0.0 & 0.0 & 15.1 \\
\hline
\end{tabular}

Finally, if we compare the MC-MV efficient mix under the first scenario (null impact of EVs) with the same efficient mix under the third scenario (penetration of the EV), it implies a reduction of almost $11 \%$ in average generating cost, $9 \%$ in risk (measured as the standard deviation) and almost $13 \%$ in emissions. Thus, if according to Marrero and Ramos-Real (2010), moving from the current mix in Canaries (highly inefficient) to the efficient frontier would suppose a gain of almost 500 million euros millions/year, the introduction of EVs (under the rough assumptions made in Section 3) would add an additional gain of 80 million euros/year in average cost, as well as a gain in risk and emission reductions. 


\section{Conclusions}

In this paper we have used the MVPT to estimate the efficiency frontier in an isolated energy system, such as the Canary Islands, to characterise the impact that the introduction of a large EV fleet may have on the efficiency of generating electricity from the point of view of a social planner. We first present the baseline frontier and evaluate the current electricity mix (strongly concentrated on fuel-oil and diesel), showing that it is very inefficient in terms of both average and volatility cost. Second, we consider two alternatives, which assume the introduction of EVs to the islands. With respect to the generation of electricity, such an introduction could reduce the minimum required share of diesel in the overall generation mix, as well as increasing the maximum feasible share of wind, increase its load factor and reduce its intermittency cost.

Comparing a particular efficiency mix in the baseline frontier with that estimated under the presence of an EV fleet, we find the following: first, the EV fleet generates a reduction of almost $11 \%$ in average generating cost, a reduction of $9 \%$ in risk (measured as the standard deviation) and a reduction of almost $13 \%$ in emissions. Second, the EV fleet increases the share of renewables (especially wind) in the efficiency mix. Lastly, it increases the complementarity between renewables and traditional technologies, thus facilitating a higher diversification within the fossil technologies, increasing the share of fuel-oil up to $15 \%$ and slightly reducing the share of natural gas in the mix to $35 \%$.

A natural line of research is to pursue an integrated approach to energy planning of a joint primary energy mix for an entire energy system, considering electricity as well as the transport sector and analysing the impact that the introduction of EVs would have on such an integrated system. (Further research should also involve analysing in more detail the relationship between the number of EVs and the reduction in the intermittency cost of renewables and other shortcomings of these technologies in terms of integration in the electric grid.

\section{References}

Awerbuch, S. (2000) 'Investing in photovoltaics: risk, accounting and the value of new technology', Energy Policy, Vol. 28, No. 14, pp.1023-1035.

Bayem, H. (2009) Apport des méthodes probabilistes aux études d'intégration des énergies renouvelables aux systèmes électriques, $\mathrm{PhD}$ dissertation in engineering, Supélec, University Paris-Sud 11 [online] http://tel.archives-ouvertes.fr/tel-00447151/en/ (accessed 15 January 2014).

Bazilian, M. and Roques, F. (Eds.) (2008) Analytical Methods for Energy Diversity and Security. Portfolio Optimization in the Energy Sector: A Tribute to the Work of Dr. Shimon Awerbuch, Elsevier, Amsterdam.

Blyth, P.L. (2011) Electric Cars on the 100\% Renewable Energy Island of Samsoe, February [online] http://projekter.aau.dk/projekter/files/52872570/SEPM4_2011 8.pdfS (accessed 15 January 2014).

Camus, C., Farias, T. and Esteves, J. (2012) 'The electric vehicles as a mean to reduce CO2 emissions and energy costs in isolated regions. The Sao Miguel (Azores) case study', Energy Policy, Vol. 43, No. 4, pp.153-165 (accessed 15 January 2014).

Codani, P., Perez, Y. and Petit, M. (2014a) 'Electric vehicles as a mobile storage device', in Yan, J. (Ed.): The Handbook of Clean Energy Systems, Chapter 217, Wiley Edition, UK. 
Codani, P., Perez, Y. and Petit, M. (2014b) 'Diversity of transmission system operators for grid integrated vehicles', Proceedings of European Energy Market Conference, EEM14, Krakow, $5 \mathrm{p}$.

de Hautecloque, A. and Perez, N.J. (2012) 'Electricity regulation', in van den Bergh, R.J. and Paccess, A.M. (Eds.): Regulation and Economics, Vol. 9, pp.377-405, Encyclopaedia of Law and Economics, 2nd ed., Edward Elgar, Cheltenham.

Estadísticas energéticas de Canarias (2011) Gobierno de Canarias, Dirección General de Industria y Energía, Canary Islands, Spain.

Feretic, D. and Tomsic, Z. (2005) 'Probabilistic analysis of electrical energy costs comparing production costs for gas, coal and nuclear power plants', Energy Policy, Vol. 33, No. 1, pp.5-13.

Finon, D. and Perez, Y. (2007) 'Transactional efficiency and public promotion of environmental technologies: the case of renewable energies in the electric industry', Ecological Economics, Vol. 62, No. 1, pp.77-92.

Glachant, J-M. and Perez, Y. (2009) 'The achievement of electricity competitive reforms: a governance structure problem?', in Ménard, C. and Ghertman, M. (Eds.): Regulation, Deregulation, Reregulation, Institutional Perspectives, Chapter 9, Edwar Elgar, UK.

Hadley, S.W. (2008) Potential Impacts of Plug-in Hybrid Vehicles on Regional Power Generation, ORNL/TM-2008/150, US Department of Energy, USA.

IAE (2013) World Energy Outlook 2013, International Energy Agency, Paris, France [online] http://www.worldenergyoutlook.org/publications/weo-2013/ (accessed 15 January 2014).

Kempton, W. and Letendre, S. (1997) 'EVs as a new source of power for electric utilities', Transportation Research, Vol. 2, No. 3, pp.157-175.

Kempton, W. and Tomić, J. (2005a) 'Vehicle to grid fundamentals: calculating capacity and net revenue', Journal of Power Sources, 1 June, Vol. 144, No. 1, pp.268-279.

Kempton, W. and Tomić, J. (2005b) 'Vehicle to grid power implementation: from stabilizing the grid to supporting large-scale renewable energy', Journal of Power Sources, 1 June, Vol. 144, No. 1, pp.280-294.

Kintner-Meyer, M.J., Douglas, B.E. and Warwick, W.M. (2007) Impacts Assessment of Plug-In Hybrid Vehicles on Electric Utilities and Regional U.S. Power Grids: Part 2: Economic Assessment, Pacific Northwest National Laboratory (a), November.

Luenberger, D.G. (1998) Investment Science, Oxford University Press, Oxford.

Markowitz, H.M. (1952) 'Portfolio selection', Journal of Finance, Vol. 7, No. 1, pp.77-91.

Marrero, G.A. and Ramos-Real, F.J. (2008) La intensidad energética en los sectores productivos en la UE-15 durante 1991 y 2005: ¿Es el caso español diferente?, Economic Reports 08-08, FEDEA.

Marrero, G.A. and Ramos-Real, F.J. (2010) 'Electricity generation cost in isolated system: the complementarities of natural gas and renewables in the Canary Islands', Renewable and Sustainable Energy Reviews, Vol. 14, No. 1, pp.2808-2818.

Marrero, G.A., Puch, L.A. and Ramos-Real, F. (2014) 'Mean-variance portfolio methods for energy policy risk management', International Review of Economic and Finance, Forthcoming.

McCarville, M. (2009) The Emergence of Electric Vehicles on Prince Edward Island and Potential Scenariosto 2030. A Guide for Policy Development, August, Working paper.

Parks, K., Denholm, P. and Markel, T. (2007) Costs and Emissions Associated with Plug-in Hybrid Electric Vehicle Charging in the Xcel Energy Colorado Service Territory, Technical Report NREL/TP-640-41410, May.

PECAN (2006) Gobierno de Canarias, Canary Islands, Spain [online] http://www.gobiernodecanarias.org/energia/doc/planificacion/pecan/ (accessed 15 January 2014). 
Perez, Y. and Ramos-Real, F.J. (2008) 'How to make a European integrated market in small and isolated electricity systems? The case of Canary Islands', Energy Policy, Vol. 36, No. 11, pp.4159-4167.

Perez, Y. and Ramos-Real, F.J. (2009) 'The public promotion of renewable energies sources in the electricity industry from the transaction costs perspective. The Spanish case', Renewable and Sustainable Energy Reviews, Vol. 13, No. 5, pp.1058-1066.

Perez, Y., Petit, M. and Kempton, W. (2014) 'Public policy strategies for electric vehicles and for vehicle to grid power', RevueD'EconomieIndustrielle, Forthcoming.

Petit, M. and Perez, Y. (2013) 'Vehicle-to-grid in France: what revenues for participation in frequency control?', European Energy Market Conference, KTH Stockholm, Mai.

Ramos-Real, F.J., Moreno-Piquero, J.C. and Ramos-Henríquez, J.M. (2007) 'The effects of introducing natural gas in the Canary Islands for electricity generation', Energy Policy, Vol. 35, No. 7, pp.3925-3935.

Rious, V. and Perez, Y. (2014) 'Review of supporting scheme for island power system storage?', Renewable and Sustainable Energy Reviews, Vol. 29, No. 1, pp.754-765.

Weisser, D. (2004) 'Power sector reform in small island developing states: what role for renewable energy technologies?', Renewable and Sustainable Energy Reviews, Vol. 32, No. 1, pp.101-127.

\section{Notes}

1 Ramos-Real et al. (2007) present a deep analysis of the energy policy objectives proposed in this document. As Marrero and Ramos-Real (2008) point out, these objectives are consistent with the Spanish strategy for improving energy efficiency through the reduction of final energy intensity.

2 Although we do not analyse it in this paper, EVs reduce $\mathrm{CO} 2$ emissions not only in electricity generation but also in the transport sector.

3 Bazilian and Roques (2008) and Marrero et al. (2014) provide a complete survey of the research applying MVPT to energy planning.

4 In Europe there are the '20-20-20' targets: $20 \%$ reduction for $\mathrm{CO} 2$ emissions, $20 \%$ reduction in energy consumption and $20 \%$ increase in efficiency

5 In continental Europe, its upper voltage levels are $400 \mathrm{kV}$ and $225 \mathrm{kV}$ and all national $400 \mathrm{kV}$ grids are interconnected to increase reliability. In each country, the transmission grid is operated by one (France) or several (Germany) regulated operators called transmission system operators (TSO).

6 In France, the line length is around 100,000 $\mathrm{km}$ for the transmission grid and 1,200,000 km for the distribution grid.

7 The first ones have the highest investment costs, but the lowest marginal costs. Typically, a peak load plant has an equilibrium point at 300 hours of running per year and 4,000 hours for a semi-base load plant.

8 IAE (2013) gives the world share of electricity generation and coal is the main resource $(40 \%)$ because it is the most abundant with an affordable investment cost even if it generates a significant amount of pollution. Nuclear is only $12 \%$ with a large disparity between countries because it has the highest investment cost and requires complex technological competencies.

9 Electricity can be classified as a tertiary or secondary energy produced from thermal, potential, wind or solar energy. For a thermal plant, the primary energy (coal, gas, uranium) is converted into mechanical energy (secondary energy) by a turbine and is transmitted to the generator to be converted into electricity (tertiary energy).

10 It is worth noting that in an electric power system the generation capacity must be installed to meet the maximum demand level of the year to prevent blackouts in a given area. 
11 In engineering studies, the goal is to solve a unit commitment problem by means of some sort of simplification, like perfect information about generation costs and demand profiles.

12 Finally, controlling the demand may also help the balance. This is known as demand response and is a part of the concept of smart grids.

13 Overload increases costly grid losses and also increases equipment temperature, which can reduce its lifespan.

14 In a distribution grid, smart demand management is once again a means of solving this issue.

15 And 1989 in UK.

16 See Finon and Perez (2007) for a comparison of the different mechanisms' performances.

17 Hydro plants have already been in operation for a long time for flexibility reasons and the potential of hydro is almost fully realised in the developed countries.

18 Currently, wind forecasts give good results three to six hours ahead. As a consequence, one MW of renewable source is not a perfect substitute for one MW of thermal predictable and manageable power and cannot deliver all the network services needed for frequency, voltage and congestion management.

19 One way to reduce these drawbacks is to require from them an additional flexible generation unit like hydro, gas turbine or electricity storage that will compensate any of their unforeseen variations. This solution is too costly; so most energy markets share the burden of the security provision costs to all the incumbent generators.

20 The net demand of consumer is the result of the local generation capabilities minus the actual consumption of the household. The result becomes less predictable because it is the result of new, still evolving, intermittent technologies. This situation is called 'producer-consumer'.

21 If we consider one million of EV or PHEV simultaneously charging at $7 \mathrm{pm}$ through a $3 \mathrm{~kW}$ plug, it will generate an additional $3 \mathrm{GW}$ peak power. Unmanaged it could cause a congestion problem, managed it can provide valuable resources for grid security.

22 Moreover, to apply MVPT we also need to estimate an average cost for each generating technology and to propose and choose a risk scenario as a reference to estimate the efficient frontier. In this research we take the results of Marrero and Ramos-Real (2010) to calculate the electricity generating efficiency frontier for the Canaries in terms of both average cost and risk. In Section 3 we summarise all these questions.

23 Nuclear, coal and hydraulic facilities are not considered. Coal has been explicitly excluded from the Canaries' energy policy since the 90s and nuclear is not deemed feasible given the size of the islands. Combined cycle plants are currently installed on Tenerife and Grand Canary, though for the time being they are running on diesel.

24 Including new energy market fleet owners, building owners, network operators, energy suppliers.

25 Other services can be classified as frequency regulation (primary and secondary control), spinning reserve, peak shaving, load shedding (demand response), or back-up services (Petit and Perez, 2013). This work is a first approach; deeper analysis of these issues is beyond the scope of this research.

26 Theses are classical usage of EV cars in France, Germany and New York.

27 We suppose an average electricity generation growth of $1 \%$ over this period. Car data was taken from Dirección General de Tráfico del Gobierno de España.

28 Although load factor depends on the characteristics of wind resource, we use average values. The introduction of EVs would allow an increase in the operating hours of wind and PV because would avoid curtailments in the delivery of energy to the network. Thus, an increase would occur in the operating load factor.

29 This value is obtained by analysing the island of Tenerife for example. A fleet of 50,000 vehicles would increase approximately $50 \mathrm{MW}$ of renewable-peak (of a total of $280 \mathrm{MW}$ ). This would allow an increase of approximately $10 \%$ of renewable generation. 
30 The reduction of intermittency cots is produced by the reduction of traditional backup power needed to ensure supply in this kind of isolated electricity system. Moreover, as we have previously noted, the base generation technology in Canaries is very expensive because uses fuel-oil.

31 The calculations were made using the 'frontier.m' function of the Matlab financial toolbox.

32 The portfolio proposed in PECAN (2006) assumes the following weights: $40.5 \%$ gas, $22.5 \%$ diesel, $7 \%$ old fuel oil, $25 \%$ wind and $5 \%$ solar. We note that, although it isalso inefficient, it is much closer to efficiency than the current mix. The PECAN, then, may be said to be a step in the right direction. 